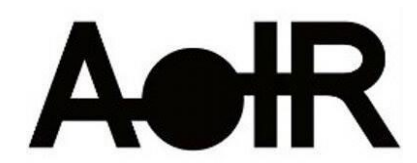

Selected Papers of \#AoIR2021:

The 22nd Annual Conference of the

Association of Internet Researchers

Virtual Event / 13-16 Oct 2021

\title{
HOW WE ARE (NOT)COPING UNDER THE NEW GAMING PUBLIC: AN EXISTENTIAL-MATERIALIST ETHNOGRAPHY OF LIFEWORLDS WITHIN (AND AGAINST) GAMER HEGEMONY
}

\author{
Mahli-Ann Rakkomkaew Butt \\ The University of Sydney
}

Following from the well-documented and unprecedented digital abuse faced by those who become deemed as 'Other' to videogames (Jane, 2016; Humphreys, 2019; Harvey, 2021), public concern has been on the rise for players, journalists, researchers, and industry workers alike. Contributing to the emerging field of Feminist Game Studies, this research seeks to intervene into the hegemonic culture fostered and maintained by what Anastasia Salter and Bridgette Blodgett describe as the 'new gaming public' (2012) which has become tied to the persistent imaginary of 'Gamers' as predominantly young males (cf. Shaw, 2013). Using qualitative mixed-methods to gather empirical data through fieldwork, surveys, and semi-structured interviews, this research presents a sociological examination of everyday struggles within (and against) hegemonic systems of oppression, reporting on how people are coping (or not coping) with exacerbated forms of sexism, racism, and homophobia pervasive across their digitally entangled and materially embedded 'lifeworlds' (Jackson, 2012).

In the past, scholars have challenged the hypermasculine Gamer stereotype, developing a better understanding about who plays videogames and how they play them (Yee, 2014). Many feminists turned to intersectional frameworks (Crenshaw, 1989) as a more nuanced approach to capture a wider range of player identities. This advocacy work became reflected in wider popular discourses. Anna Everett declares, "a sign of our millennial times" is that gaming journalists are more willing than ever to "raise concerns about race, gender, and sexuality discourses in gaming culture and the gaming industry complex," (2017, p. ix). Following the pursuit to improve representation in the workplace, inclusivity measures and accessibility policies had fast become an industry hot topic. Seen in the widespread uptake of 'equal opportunity' hires and declared commitments to fixing the proverbial 'leaky pipelines' flowing from higher education into the workforce (Harvey, 2021), companies have sought to better retain and grow their (body)count of minorities as both consumers and workers. In many ways, challenging the stereotype of Gamers has been a crucial step towards fostering a sense of 'diversity' or 'inclusivity'.

Suggested Citation (APA): Butt, M. (2021, October). How we are (not)coping under the New Gaming Public: An existential-materialist ethnography of lifeworlds within (and against) Gamer hegemony. Paper presented at AoIR 2021: The 22nd Annual Conference of the Association of Internet Researchers. Virtual Event: AolR. Retrieved from http://spir.aoir.org. 
Despite attempts to improve representation, however, the new gaming public is still seen to be in the midst of a cultural 'civil war' (Vossen, 2018, p. 4). In the battle over who should represent or be represented, skirmishing stakeholders and those caught in the crossfire must all remain hypervigilant (Golding \& van Deventer, 2016). Marginalised players continue to worry about their personal safety when participating in online games, seeing gendered, homophobic, racially targeted hate and digital harassment to simply be par for the course (Jane, 2016). To date, the main solution for individuals has been to seek out better coping strategies to avoid and navigate an increasingly hostile environment (Cote, 2017; Harvey, 2021). Since there can be no rest or reprieve from ever-looming threats (Massumi, 2015), there is an urgent need to find other interventions.

In response to the new gaming public, feminist voices have frequently advocated greater inclusivity across player communities, industries, journalism, and games academia. However, much of this advocacy work anchors onto discussions about improving poor representation. Accordingly, feminist critiques of sexist, racists, and homophobic depictions of in-game characters will often also seek to promote the 'diversification' of games industry workforces in order to achieve overall 'greater representation' from the ground up. While this work is crucial and should not be discounted, I contend that we must also diversify how we discuss social justice issues. To paraphrase Amanda Phillips (2020) and Clare Hemmings (2012): We must provide different accounts of lived experiences, but we must also learn how to tell these stories differently. Therefore, this research promotes a greater appreciation for a wider plethora of feminist approaches by re-establishing existential-materialism as another vehicle for revolution in pursuit of social justice.

This paper argues that existential-materialism is a useful generative tool for feminist games, media, internet, and cultural researchers to investigate how people cope (or do not cope) with the hegemony of the new gaming public as it crucially apprehends the medium of videogames as part of people's lifeworlds embedded in materiality rather than separate from everyday life. Departing from the liberalist premise that diversity can be fostered from representation alone, this research, crucially, explores another feminist approach to address the hegemony of videogames. Instead, I stake the claim that we must return our attention back to moments of resistance as the fundamental site for political transformation. In doing so, this research stylizes '(not)coping' to challenge the assumed dichotomy of 'not coping' as a failure 'to cope'. Rather than treating 'coping' and 'not coping' as positive and negative binaries, (not)coping highlights the liminality in-between these affective states. In this paper, I argue that moving from 'coping' towards the refusal to cope with status quos is a transcendence of the Self (Hemming, 2012) first needed to generate alternative knowledges necessary for socio-cultural and political revolution. Therefore, (not)coping infers critical potency: a transformative affective space for the refusal to cope within (and against) hegemony. Ultimately, in posing existential-materialist questions about the ubiquity of everyday struggles, this research provides new possibilities for action and directions for future research.

Overall, this research explores an alternative approach to studying digital gaming cultures in a manner that does not necessitate a focus on play, playing, or creating play. 
Therefore, it is not a study about particular videogames, nor is it really a study about 'gamers' or 'players' themselves. Instead, I examine the following three different sites:

1. Ontopowered Lifeworlds (interviews with women who played videogames with their romantic partners),

2. Intoxicated Lifeworlds (ethnography of public and industry social events), and

3. Political Lifeworlds (autoethnography on becoming a 'diversity worker').

When pointing to the ubiquity of feelings, everyday struggles, and experiences of (not)coping, this research takes on a feminist instruction to include those who are not necessarily 'gamers' or 'players', but who all—nonetheless—have meaningful experiences in their (dis)connections to videogames. In doing so, this research presents an overarching argument in favor of giving more value to the most marginalized and often overlooked in the discipline of Game Studies, and how their stories are significant, necessary, and meaningful to any and all discussions about gaming cultures. In the discipline of Game Studies, the methods of investigation are frequently configured around the study of play, players, or the creation of play; however, we must take greater stock of people's lifeworlds, including non-players, non-play relationship dynamics, and non-play centric spaces in our intersubjective relations to videogames and beyond the hegemonic new gaming public.

\section{References}

Cote, A. C. (2017). "I Can Defend Myself": Women's Strategies for Coping with Harassment while Gaming Online. Games and Culture, 12(2), 136-155.

Everett, A. 2017). Foreword. In J. Malkowski \& T. M. Russworm (Eds.), Gaming representation: race, gender, and sexuality in video games (pp. ix-xiv). Indiana University Press.

Golding, D. \& van Deventer, L. (2016). Gamer Changers. Affirm Press.

Harvey, A. (2021). Making the grade: Feminine lack, inclusion, and coping strategies in digital games higher education. New Media \& Society, 1-17.

doi:10.1177/1461444820986831

Hemmings, C. (2012). Affective solidarity: Feminist reflexivity and political transformation. Feminist Theory, 13(2), 147-161.

Humphreys, S. (2019). On Being a Feminist in Game Studies. Games and Culture, 14(7-8), 825-842.

Jackson, M. (2013). Lifeworlds: Essays in Existential Anthropology. University of Chicago Press.

Jane, E. A. (2016). Misogyny Online: A Short (and Brutish) History. SAGE Publishing.

Massumi, B. (2002). Parables for the Virtual: Movement, Affect, Sensation. Duke University Press. 
Phillips, A. (2020). Negg(at)ing the Game Studies Subject: An Affective History of the Field. Feminist Media Histories, 6(1), 12-36.

Salter, A. \& Blodgett, B. 2012. Hypermasculinity \& Dickwolves: The Contentious Role of Women in the New Gaming Public, Journal of Broadcasting \& Electronic Media, 56(3), 401-416.

Shaw, A. (2013). On Not Becoming Gamers: Moving Beyond the Constructed Audience. Ada: A Journal of Gender, New Media, and Technology, (2). doi:10.7264/N33N21B3

Vossen, E. (2018). On the Cultural Inaccessibility of Gaming: Invading, Creating, and Reclaiming the Cultural Clubhouse [Unpublished PhD thesis]. University of Waterloo.

Yee, N. (2014). The Proteus Paradox: How Online Games and Virtual Worlds Change Us and How They Don't. Yale University Press. 